\title{
A REFoRMa do ENSINO MÉdio POR MEIO dA LEI No 13.415/2017 E SEUS IMPACTOS NO ENSINO MÉdIO INTEGRADO DOS INSTITUTOS FEDERAIS
}

\author{
THE REFORMATION OF HIGH SCHOOL THROUGH LAW NO. \\ 13,415/2017 AND ITS IMPACTS ON EDUCATION INTEGRATED MEDIUM \\ OF FEDERAL INSTITUTES
}

DOI: http://dx.doi.org/10.23926/RPD.2526-2149.2019.v4.n2.p869-886.id560

\author{
Silvia Maria dos \\ Santos Stering \\ Pós doutora pelo Programa \\ de Pós Graduação em \\ Educação (UFMT e Unesp \\ Rio Claro/SP) \\ Doutora em Educação \\ (Unesp Rio Claro/SP) \\ Pedagoga no Instituto \\ Federal de Mato Grosso \\ (PROEN/IFMT) \\ silvia.stering@ifmt.edu.br
}

\section{Joyce Mary Adam}

Pós-doutorado na França,

Universidade de Paris X e no

CESDIP- Université de

Versailles França

Doutora em Educação

(Unicamp)

Professora Associada da

Universidade Estadual

Paulista Júlio de Mesquita

Filho (UNESP)

joyce.adam@unesp.br
Resumo: Este artigo evidencia os impactos da Reforma do Ensino Médio - REM no Ensino Médio Integrado - EMI nos Institutos Federais - IF`s via pesquisa qualitativa, bibliográfica e documental. Analisamos normativas e legislações que tratam dos itinerários formativos na Lei $\mathrm{N}^{\circ}$ 13.415/2017 em articulação com as reformas de cunho neoliberais que almejam reduzir gastos públicos e encaminhamento da classe trabalhadora para o mercado de trabalho, além de comparar com o fenômeno ocorrido no Chile na década de 80. O texto reflete as concepções de Educação Profissional e Tecnológica - EPT com foco na proposta de EMI, que demanda uma visão crítica sobre o contexto no qual o sujeito está inserido e busca na tecnologia a produção de conhecimentos que visem à formação integral. $\mathrm{O}$ estudo aponta que a lei não impactou a oferta dos cursos, uma vez que os IF"s não aderiram à mesma, tendo em vista que se destacam pela qualidade e condições de funcionamento necessárias à formação humana mediante integração entre ciência, tecnologia, cultura e trabalho como eixos norteadores do currículo. A REM consiste no fortalecimento da dualidade educacional e de uma orientação mercadológica; precarização da docência que não afetou os Institutos Federais, dado a sua condição de autarquia.

Palavras-chave: Reforma do Ensino Médio. Impacto no Ensino Médio Integrado. Institutos Federais.

\begin{abstract}
This article highlights the impacts of the High School Reform - REM on Integrated High School - EMI in the Federal Institutes - IF's via qualitative, bibliographical and documentary research. We analyze normative and legislation dealing with the formative itineraries in Law No. 13,415 / 2017 in conjunction with neoliberal reforms that aim to reduce public spending and the working class to the labor market, and compare with the phenomenon that occurred in Chile in the decade. of 80. The text reflects the conceptions of Professional and Technological Education - EPT focusing on the proposal of EMI, which demands a critical view on the context in which the subject is inserted and seeks in technology the production of knowledge aimed at integral formation. The study points out that the law did not impact the offer of courses, since the FI`s did not adhere to it, since they stand out for the quality and operating conditions necessary for human formation through the integration between science, technology, culture and work as guiding axes of the curriculum. EMN consists in strengthening educational duality and market orientation; precarious teaching that did not affect the Federal Institutes, given its condition of autarchy.
\end{abstract}

Keywords: High School Reform. Impact on Integrated High School. Federal Institutes. 


\section{INTRODUÇÃO}

Ao longo do tempo, o ensino médio no Brasil vem se configurando como um campo de disputas ideológicas, que perpassam as políticas públicas a ele direcionadas na perspectiva de via de mão dupla, cuja marca é a indefinição e a busca de identidade, uma vez que este "rito de passagem" vivenciado não se configura apenas como uma celebração.

O cenário político no Brasil evidencia que o campo de disputa que perpassa o Ensino Médio está se avigorando em função da política neoliberal vigente, mediante mundialização do capital, sob a égide da globalização da qual o Brasil não está imune. Nesta direção, o Ensino Médio, na perspectiva de um processo de educação formal, com foco na formação do trabalhador, tem sido desenvolvido com a intenção de fazer cumprir as premissas do mundo do capital. Assim, a oferta em questão se dá em detrimento da formação humana, que, em um contexto geral, é encampado e desenvolvido privilegiando a competitividade que acaba por solapar, na prática política, as prerrogativas de cidadania que sustentam o ideário de educação em sua plenitude (LIMA, 2006).

No exato dia em que os Institutos Federais, instituição criada no governo de Luiz Inácio Lula da Silva, por meio da Lei No 11.892/08, com a intenção de ressignificar a Educação Profissional e tecnológica no Brasil, completam 10 (dez) anos de existência, o Ministério da Educação publicou no Diário Oficial da União no dia 28 de dezembro de 2018 a Portaria No 1.432, que estabelece os referenciais para a elaboração dos itinerários formativos criados pela reforma do ensino médio.

A Portaria $\mathrm{N}^{\mathrm{o}} 1.432$ de 28 de dezembro de 2018, na contramão dos avanços no que tange as intenções positivas em relação à educação do trabalhador e relativos ao campo de disputas que envolvem o Ensino Médio no Brasil desde 1988, em função da promulgação da Constituição Federal, se configura como a retomada do que propunha o Decreto $n^{\circ}$ 2.208/1997, que determinava a separação obrigatória entre o ensino médio e a educação profissional, que consagra a dualidade da Educação no Ensino Médio na esfera legal.

Em um contexto histórico, no Brasil, após a promulgação da Constituição Federal, muitas tem sido as transformações pelas quais o Ensino Médio tem passado e dentre as quais podemos destacar:

- 1998: Debate e aprovação das diretrizes do EM de acordo com a nova legislação da

LDB de 1996;

○ 2002: Seminário Nacional sobre reforma do ensino médio; 
- 2007: Criação do FUNDEB com a promessa de garantir a universalização do EM (Lei $\mathrm{N}^{\circ}$ Lei $\left.\mathrm{n}^{\circ} 11.494\right)$;

- 2007: Lançamento do Plano de Ações Articuladas pelo MEC;

· 2009: Instauração do Novo ENEM;

· 2010: Criação do Ensino Médio Inovador;

· 2010: Criação do Grupo de Trabalho da Reforma do Ensino Médio pelo CONSED;

○ 2012: Aprovação das Diretrizes Curriculares Nacionais para o Ensino Médio pelo CNE;

- 2013: Proposição do Projeto de Lei (PL 6840/2013);

· 2014: Aprovação do Plano Nacional da Educação (PNE) em que a Meta 3.1: visa:

Institucionalizar programa nacional de renovação do ensino médio, a fim de incentivar práticas pedagógicas com abordagens interdisciplinares estruturadas pela relação entre teoria e prática, por meio de currículos escolares que organizem, de maneira flexível e diversificada, conteúdos obrigatórios e eletivos articulados. (BRASIL, 2014).

Desde o ano de 2016, experienciamos a ascensão de uma perspectiva conservadora que foi intensificada, sobretudo após o impeachment de Dilma Rousseff do PT e a chegada à presidência do seu vice, Michel Temer do MDB, que colocou em prática uma agenda neoliberal de associação aos interesses do capital. A reforma do ensino médio, inicialmente conhecida como Medida Provisória 746 (MP 746/2016) transformou-se na Lei № 13.415/2017, após a aprovação no Congresso Nacional, constituindo-se num ato do governo federal alinhado às tendências liberais.

Aprovada ainda em 2016 durante o governo Michel Temer, a reforma divide o currículo desta modalidade entre os conteúdos comuns que devem ser oferecidos a todos os estudantes e que são estabelecidos pela Base Nacional Comum Curricular (BNCC), e os conteúdos específicos às áreas de matemática, linguagens, biologia, ciências humanas e formação técnica e profissional. Os itinerários formativos se referem a esta última etapa.

Com o intuito de ganhar a confiança da população com a reforma, houve a disseminação de propagandas que cultivaram, sobretudo, a expectativa de flexibilidade do ensino médio e a conquista de autonomia do estudante. Da mesma forma, utilizou-se o discurso do caos para justificar as mudanças aceleradas impostas pelo governo, explorando ao máximo informações sobre os problemas existentes nesta etapa de ensino, tais como o alto índice de evasão e o baixo desempenho dos alunos em avaliações padrões nacionais. 
Na prática, o que se dá é a opção por uma reforma seletiva ao invés de um investimento ampliado, com base em experiências que embora tenham sido pouco aplicadas na rede pública, são consideradas de sucesso nos locais onde ocorreram.

Afirmam Moura e Filho (2017) que:

\begin{abstract}
Ao fazer política de terra arrasada sobre o EM público, o discurso oficial omite experiências positivas, em particular no ensino médio integrado à educação profissional (EMI) realizado em inúmeras escolas estaduais e na rede pública federal (Cefet, Institutos Federais, escolas vinculadas às universidades federais, Colégio Pedro II e UTFPR). Tais escolas se destacam em qualidade porque, dentre outras razões, reúnem o que em linhas anteriores denominamos condições de funcionamento necessárias, aliadas à concepção de formação humana integral, com a integração entre ciência, tecnologia, cultura e trabalho como eixos norteadores do currículo. (MOURA; FILHO, 2017, p. 120).
\end{abstract}

Se a ideia da reforma de ampliação do Ensino Médio das atuais 2.400 horas para 3 mil horas se apresenta como interessante em um primeiro instante, a dúvida habita na inviabilidade de sua aplicação na rede pública sem que haja financiamento estatal de grande porte, tendo em vista a redução de investimentos imposta pelo governo Temer e em acelerado processo de continuidade no governo Bolsonaro, o que tem originado grandes dificuldades para os gestores educacionais terem que resolver.

\title{
2 COMPREENDENDO O FENÔMENO
}

Historicamente, o ensino médio em sua gênese evidenciava intenções propedêuticas apenas. A transformação da intenção propedêutica para a formação profissional da oferta surgiu com as reformas educacionais propostas por Francisco Campos, em 1930, com a criação do ensino profissionalizante destinado às "classes menos favorecidas", que na Rede Federal de Educação ficou a cargo das Escolas de Aprendizes e Artífices, criadas no ano de 1909 pelo então presidente Nilo Peçanha e que passa a oferecer no ano de 1930 o Ensino Médio Profissionalizante.

O fato de a educação do trabalhador nascer sob a égide do governo federal em 1909, é no mínimo curioso. O que leva a considerar às intenções dessa decisão, fazendo-nos acreditar que, desde o princípio da criação da Rede Federal de Ensino, no ano de 1909, suas finalidades tiveram como fundamento o controle por parte do Estado, de maneira clara e objetiva da educação do trabalhador, conforme suas necessidades.

Podemos comprovar essa assertiva analisando a normativa que instituiu a Rede de Ensino Profissional no Brasil. Nela é possível ver que o sistema federal de Educação Profissional deveria ofertar o ensino de ofícios, de forma a atender às especificidades da 
indústria e dos serviços em cada estado, sob a luz das justificativas oficiais, conforme pode-se observar:

\begin{abstract}
Art. $2^{\circ}$ Nas Escolas de aprendizes Artifices, custeadas pela União, se procurará formar operarios e contra-mestres, ministrando-se o ensino pratico e os conhecimentos technicos necessarios aos menores que pretenderem aprender um officio, havendo para isso, até o numero de cinco, as officinas de trabalho manual ou mecanica que forem mais convenientes e necessarias no Estado em que funccionar a escola, consultadas, quanto possivel, as especialidades das industrias locaes. (BRASIL, 1909).
\end{abstract}

Nessa mesma linha de raciocínio, Luiz Antonio Cunha (2000, p. 65-66) descreveu que seria necessário promover "às classes proletárias os meios de vencer as dificuldades sempre crescentes da luta pela existência", de forma a "habilitar os filhos dos desfavorecidos da fortuna com o indispensável preparo técnico e intelectual, como fazê-los adquirir hábitos de trabalho profícuo".

As considerações apresentadas na introdução do Decreto no 7.566, de 1909, demonstravam as motivações vinculadas à criação da Escola de Aprendizes Artífices. Nelas ficam evidentes que o governo brasileiro buscava não só resolver os problemas de ordem econômica e política vigentes naquele tempo histórico, como objetivava a formação da força de trabalho industrial de forma imediatista para atender ao capitalismo que avançava pelo Brasil.

Considerando:

que o aumento constante da população das cidades exige que se facilite às classes proletárias os meios de vencer as dificuldades sempre crescentes da luta pela existência: que para isso se torna necessário, não só habilitar os filhos dos desfavorecidos da fortuna com o indispensável preparo técnico e intelectual, como faze-los adquirir hábitos de trabalho profícuo, que os afastará da ociosidade ignorante, escola do vício e do crime; que é um dos primeiros deveres do Governo da Republica formar cidadãos uteis à Nação. (BRASIL, 1909, p. 01)

Para Nilce Vieira Campos Ferreira (2014, p. 56), a Educação Profissional firmar-se-ia como "um segmento na relação escola-trabalho. Essa discriminação não foi fruto de ideários trabalho e educação, mas de relações sociais concretas, nascidas no campo da produção". Essa foi uma relação que perdurou nos primeiros anos de existência das escolas técnicoprofissionalizantes, fica-nos claro que somente após os anos de 1994, por força da Lei no 8.948, de 8 de dezembro é que este cenário é modificado e motiva o processo de expansão e ressignificação da Rede Federal, a partir da organização dos Institutos Federais, por meio do Decreto $n^{\circ} 6.095$, de 24 de abril de 2007 e a posterior Lei de criação, Lei n 11.892 de 29 de dezembro de 2008. 
Partindo do pressuposto de que para que um país capitalista se desenvolva em bases sólidas e acima de tudo em bases democráticas, se fazem necessários investimentos em educação. E essa se constitui a proposta do segundo mandato do presidente Luiz Inácio Lula da Silva, sobretudo no que se refere à educação profissional, com investimentos maciços em relação à implantação e ampliação da Rede Federal de Educação Tecnológica, recentemente transformada em Institutos Federais, que passa a ofertar, além do Ensino Médio Técnico, Cursos Superiores de Tecnologia, Engenharias e Bacharelados, também as Licenciaturas.

O Instituto Federal de Educação, Ciência e Tecnologia de Mato Grosso, propõe-se capacitar profissionalmente jovens e adultos para o mundo e o mercado do trabalho. Nesse contexto, há de se preparar esses técnicos para que tenham alguns diferenciais. Entre esses diferenciais estão a criticidade de pensamento e a capacidade de iniciativa. Visto que via capacidade de iniciativa, o indivíduo não mais executa ordens simplesmente, mas faz parte do processo produtivo de forma pró-ativa. Além disso, há uma preocupação em todo o ensino de base, com a formação de uma base sólida para a construção da cidadania do indivíduo que inclui a questão da consciência política, social e acima de tudo de um posicionamento ético.

Diante do exposto, o jovem do século XXI vive a busca da reformulação do ensino médio, mediante algo novo e com certo diferencial, que vai desde o ambiente físico da escola e culmine com as questões voltadas para a didática, cuja especificidade pode estar voltada para o mercado de trabalho, assim como para o preparo para os vestibulares e ENEM. A expectativa em torno deste "rito de passagem, é a de que ele contribua para melhorar a autoestima dos discentes e docentes, além de ratificar a escala de valores sociais e escolar, bem como aumentar os laços de solidariedade entre os jovens, principalmente de baixa renda". (GENNEP, 1978). Contudo, tal possibilidade é descartada quando o jovem se quer foram questionados quanto qual é do seu ponto de vista o Ensino Médio desejável, no sentido de atender suas expectativas e recebem a Reforma de maneira imposta.

O Observatório da Juventude declara que,

\begin{abstract}
Todas as experiências de Reformas Curriculares no Brasil e em outros países indicam que elas precisam ser construídas no diálogo com a sociedade como um todo (incluindo gestores e especialistas) e, especialmente, com professoras/es e comunidades escolares. A MP é, ao contrário, parcial em seus diagnósticos e perspectivas. Não se alimenta do debate educacional, ao contrário, tenta silenciá-lo. (OJ, 2017, p. 2)
\end{abstract}

Fica evidente, portanto, que a Reforma do Ensino Médio consiste em um retrocesso, uma vez que desconsidera o processo histórico que propiciou à inclusão destes componentes nos currículos e a importância que reside em cada um. A não obrigatoriedade de componentes 
curriculares, que assumem um caráter acessório, empobrece o currículo escolar de forma a deixa-lo pobre, frágil e incompleto, evidenciando a lógica da formação aligeirada e de caráter instrumental.

O Artigo 36 da Lei $\mathrm{n}^{\circ} 13.415$ apresenta o itinerário formativo a ser possibilitado nos cursos de Ensino Médio. O texto orienta que o currículo relativo aos cursos nesta modalidade seja composto pela Base Nacional Comum Curricular e por itinerários formativos específicos, a serem definidos pelos sistemas de ensino, cuja ênfase esteja nas seguintes áreas de conhecimento ou de atuação profissional:

I - Linguagens e suas tecnologias;

II - Matemática e suas tecnologias;

III - Ciências da natureza e suas tecnologias;

IV - Ciências humanas e sociais aplicadas; e

V - Formação técnica e profissional.

Na prática, sessenta por cento $(60 \%)$ do currículo será composto de um conteúdo mínimo obrigatório, a ser definido pela Base Nacional Curricular Comum (BNCC), que irá orientar a forma pela qual os componentes curriculares serão organizados nos projetos pedagógicos dos cursos. Embora a BNCC relativa ao Ensino Médio ainda não esteja definida, já é consenso que os currículos do ensino médio devem compreender, obrigatoriamente, o estudo da língua portuguesa e da matemática, áreas historicamente valorizadas em nossa sociedade e que já contam com maior carga horária nos currículos escolares.

Os demais $40 \%$ restantes do currículo serão destinados aos chamados itinerários formativos, onde supostamente o estudante poderá fazer a escolha entre as cinco áreas de conhecimento mencionadas na Lei, determinadas em conformidade com a proposta da escola: linguagens, matemática, ciências da natureza, ciências humanas e formação técnica e profissional. Cada escola deverá oferecer aos estudantes pelo menos um dos cinco itinerários formativos, o que se configura ao nosso ver em um problema. Inexistem formas de controle para o acompanhamento das ofertas dos itinerários, o que não significa que em dado bairro ou cidade existam a ofertas de todos os itinerários, já que o estudante tem a liberdade de escolher o que melhor atende a sua vocação.

A ideia de que as escolas devam oferecer possibilidades de formação que supostamente seriam escolhidas em conformidade com os interesses dos estudantes, é perpassada por um fator limitante relativo às condições de cada instituição de ensino. 
Como muito bem exemplificado pelos Institutos Federais em todo o Brasil, a oferta dos cursos técnicos demanda laboratórios, equipamentos e diversos materiais de consumo. Dependendo do eixo tecnológico, o investimento necessário para a oferta de um curso técnico é muito grande, o que levou o governo federal, quando da criação da nova institucionalização, realizar um investimento significativo em recursos humanos e materiais, a fim de conferir excelência à instituição e aos resultados dos trabalhos desta.

Além disso, se faz necessária a contratação de servidores técnicos - administrativos e professores especialistas em cada área de formação. No caso dos Institutos Federais o Plano de Desenvolvimento Institucional de cada campi previa e fez cumprir o número necessário de servidores docentes e técnicos administrativos, além de investir fortemente no processo de formação continuada destes, que soma na Rede Federal mais de 50\% do total de seus servidores com titulação de mestres e doutores em todo o Brasil, fato que a Lei $\mathrm{n}^{\circ} 13.415$, intenta tentar resolver com a possibilidade de contratação de profissionais com notório saber (Figura 1).

Figura 1 - Pontos importantes da Reforma do Ensino Médio

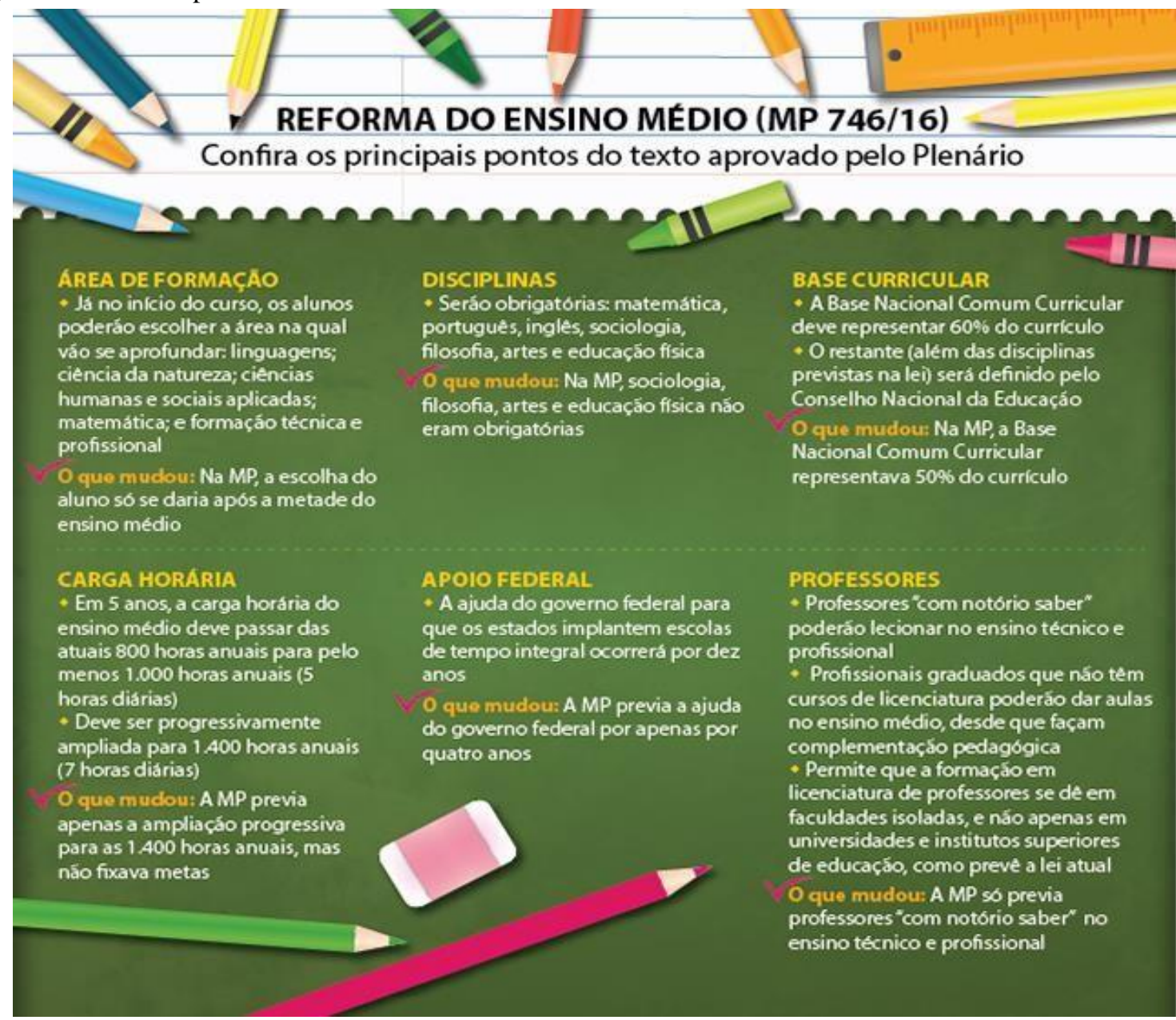

Fonte: http://www2.camara.leg.br/camaranoticias/imagens/imgNoticiaUpload1481745081473.jpg ( acesso em 12/09/2019). 
Conforme se pode observar na Figura 1, o texto evidencia que toda a discussão relativa à sua operacionalização deverá ser discutida nas próprias instituições de ensino. Inexiste preocupação em relação à continuidade de estudos ou à gestão de investimentos e de pessoal, diferente do que acontece na estrutura dos Institutos federais em todo o Brasil. Mediante discurso relativo à flexibilização curricular e de que os estudantes poderão escolher o percurso e itinerário que querem fazer e escolher o que querem estudar, em conformidade com sua área de formação, a Lei em tela acaba se apresenta como vaga e inespecífica.

Uma vez que a definição dos itinerários formativos será efetivada pelos sistemas de ensino, e não pelos estudantes, as instituições de ensino poderão ofertar, na prática, poucas opções de escolha aos estudantes, uma vez que têm a obrigatoriedade de realizar a oferta de somente um único itinerário formativo. Outro agravante diz respeito ao processo de georreferenciamento que integra alguns sistemas de ensino, que determina que o estudante se matricule na instituição de ensino mais próxima de sua residência, impossibilitando a escolha de Instituições que ofereçam itinerários formativos de interesse do estudante.

A proposta prevê a diversificação de programas ou tipos de estudo, que devem ser estimulados por meio de alternativas, mediante os interesses dos estudantes e as demandas do meio social, consideradas as opções realizadas pelos próprios estudantes. Em conformidade com o parágrafo $5^{\circ}$ do Artigo 36, o concluinte do Ensino Médio poderá retornar e concluir outro itinerário formativo, caso haja vaga, contudo, tal possibilidade acarretaria atrasos formativos ao estudante.

\section{A Imprescindibilidade da FlexibilizaÇÃo E A NegaÇão do Aligeiramento Curricular no EnSino Médio}

Condição imprescindível para o processo de organização ou reorganização do currículo em se tratando do Ensino Médio consiste na flexibilidade. Partindo da ideia de que a realidade é dinâmica, em que as demandas do mundo e do mercado de trabalho estão em pleno processo de transformação, podemos afirmar que o futuro se apresenta como incerto (MOURA, 2007). A consciência plena quanto às mudanças que perpassam o mundo contemporâneo é o que justifica a necessidade crescente do desenvolvimento de práticas educativas mediante proposta curricular flexível e aberta.

Entretanto, importante se faz levar em conta que flexibilidade não se configura como sinônimo de aligeiramento ou precarização dos processos formativos. O desenvolvimento de uma prática educativa que tenha foco no futuro demanda dos professores a responsabilidade 
com a formação de cidadãos críticos, reflexivos, éticos e comprometidos com as transformações sociais e coletivas voltadas para a construção de uma sociedade justa e igualitária. Portanto, qualquer possibilidade de formação aligeirada e reducionista se coloca em direção contrária (MOURA, 2007).

A prática de um currículo flexível sugere que a organização do processo ensinoaprendizagem se dê de forma a permitir ao estudante diferentes possibilidades ao longo de sua caminhada acadêmica. Neste sentido, os itinerários formativos flexíveis possibilitarão avanços significativos quando houver condições para tal, ou garantir estudos de complementação em dadas áreas de conhecimentos científicos e tecnológicos que podem ser necessários em dado instante do exercício da profissão, ou simplesmente de interesse do estudante.

Daí a necessidade de repensarmos as funções do ensino médio e sua organização curricular, na perspectiva de um ato importante no processo educativo. Contudo, Moura (2007) destaca que é igualmente importante ponderar que propostas de organização curricular devem considerar também:

a) A garantia de financiamento público para apoiar as ações a serem desenvolvidas;

b) O plano de capacitação permanente de docentes, técnico-administrativos e gestores;

c) A infraestrutura adequada de salas de aula, laboratórios, biblioteca, espaço para atividades artístico-culturais;

d) A organização curricular diferenciada para os alunos do turno noturno;

e) A busca de um diálogo com interlocutores externos ao próprio sistema acadêmico;

f) A colaboração com empresas e instituições para a realização de estágios curriculares;

g) O plano de implementação, acompanhamento e avaliação dos cursos.

$\mathrm{Na}$ atualidade visualizamos várias possibilidades de organização do ensino médio, as quais refletem a flexibilidade no que se refere à legislação e documentos legais orientadores da oferta. Cada instituição de educação e ensino pode planejar e executar a melhor forma de organização do ensino médio, de forma a considerar suas limitações e realidade.

Moura (2007) destaca que ninguém mais do que o próprio grupo, o próprio coletivo conhece a sua realidade e, portanto, está hábil para tomar as decisões relativas ao currículo que irá desenvolver. Qualquer proposta de reforma que desconsidere tais questões, estará fadada ao 
insucesso ou não poderá ser implementada em sua totalidade, gerando dificuldades que poderão distorcer o processo educativo pretendido.

Os Institutos Federais se caracterizam por certa especificidade, pois possuem estrutura diferenciada, tendo em vista que foram criados por meio da junção e transformação de antigas autarquias profissionais, já em funcionamento, e que compunham a nova rede, exceto a Universidade Tecnológica.

Criados pela Lei 11.892, de 29 de dezembro de 2008, que institui a Rede Federal de Educação Profissional, Científica e Tecnológica, os Institutos Federais de Educação, Ciência e Tecnologia, são instituições de educação superior, básica e profissional, pluricurriculares e multicampi, especializados na oferta de educação profissional e tecnológica em diferentes modalidades de ensino, com base na conjugação de conhecimentos técnicos e tecnológicos às suas práticas pedagógicas. Os Institutos Federais compõem a Rede Federal de Educação Profissional, Científica e Tecnológica.

No Brasil, a forma integrada da educação profissional ao ensino médio foi orientada mediante Decreto $\mathrm{n}^{\circ}$ 5.154/2004 (BRASIL, 2004), e seu conteúdo foi incluído na Lei de Diretrizes e Bases da Educação Nacional (LDB), pela Lei no 11.741, de 2008 (BRASIL, 2008a). Trata-se de uma das modalidades de articulação entre a educação profissional técnica e o ensino médio, e seu sentido encontra-se no compromisso ético e político de assegurar aos estudantes, em um único currículo, o direito à formação profissional, sem que esta substitua a formação geral, conforme descrito no parágrafo segundo do artigo 36 da versão original da LDB.

Contudo, sua concepção, vai além do aspecto formal da integração entre as finalidades formativas, assegurando também a integração entre trabalho, ciência e cultura, dimensões fundamentais da prática social, mediante projeto político-pedagógico que visa à formação integral e integrada dos estudantes. Ao ser visualizado como uma concepção de formação humana, o EMI contrai um sentido filosófico e epistemológico que não aceita a pura e simples junção de disciplinas consideradas de formação profissional ou de formação geral no currículo.

Antes, ele busca articular a compreensão da relação econômica, social e histórica entre essas dimensões da prática social, por meio de um currículo que leve à apreensão de conceitos como sistema de relações de uma totalidade concreta que se pretende explicar, compreender e transformar (RAMOS, 2017).

Diante do exposto, podemos afirmar que a Reforma do Ensino Médio não atingiu os cursos de Ensino Médio Integrado ofertados e desenvolvidos nos Institutos Federais, tendo em vista que a instituição ao utilizar do princípio de autonomia que é correlata à sua natureza 
jurídica autárquica federal inerente às entidades pertencentes à Rede Federal de Educação Profissional e Tecnológica.

No que tange ao aspecto legal, o conceito de autarquia está evidente no artigo $5^{\circ}{ }^{\circ}$, inciso I, do Decreto-lei n. ${ }^{\circ}$ 200/67, que a delibera como serviço autônomo, criado por lei, com personalidade jurídica, patrimônio e receita própria, para executar atividades típicas da administração pública, que requeiram, para seu melhor funcionamento, gestão administrativa e financeira descentralizada.

A Lei n. ${ }^{\circ}$ 11.892/08 institui a Rede Federal de Educação Profissional e Tecnológica no Brasil, a qual compreende também os institutos federais de educação. A compreensão dessa normativa é importante, uma vez que os institutos federais apresentam natureza jurídica de autarquia federal contemplados com autonomia administrativa, patrimonial, financeira, didático-pedagógica e disciplinar inerente às autarquias conforme artigo $1 .^{\circ}$,

\footnotetext{
Art. 1o Fica instituída, no âmbito do sistema federal de ensino, a Rede Federal de Educação Profissional, Científica e Tecnológica, vinculada ao Ministério da Educação e constituída pelas seguintes instituições:

I - Institutos Federais de Educação, Ciência e Tecnologia - Institutos Federais;

II - Universidade Tecnológica Federal do Paraná - UTFPR;

III - Centros Federais de Educação Tecnológica Celso Suckow da Fonseca - CEFETRJ e de Minas Gerais - CEFET-MG;

IV - Escolas Técnicas Vinculadas às Universidades Federais.
}

Parágrafo único. As instituições mencionadas nos incisos I, II e III do caput deste artigo possuem natureza jurídica de autarquia, detentoras de autonomia administrativa, patrimonial, financeira, didático-pedagógica e disciplinar. (BRASIL, 2008).

As entidades autárquicas fazem parte da administração direta na estrutura do Estado. O termo autarquia está relacionado à faculdade/possibilidade conferida pelo próprio Estado para uma instituição/organização para fins de execução descentralizada de serviços de interesse estatal ou da coletividade, portanto, sujeitos à fiscalização da administração direta. A autarquia é uma extensão do Estado, integrando o aparelho estatal com função pública típica, assim, o Estado não se desfaz da sua prerrogativa de controle, mais descentraliza sua gestão para atender as demandas específicas de maneira mais adequada.

A organização política e administrativa dos institutos federais está evidenciada na seção IV, "Da Estrutura Organizacional dos Institutos Federais", da lei de criação, na qual estão definidos e caracterizados alguns cargos e conselhos que fazem parte do organograma de todas as instituições do conjunto dos Institutos Federais. Em função de sua estrutura multicampi, observa-se a existência de uma instância central de tomada de decisão composta pelo Conselho 
Superior (Consup), Colégio de Dirigentes (Codir) e a Reitoria e outra instância descentralizada de tomada de decisão composta especificamente pelos servidores de cada campus.

Os órgãos máximos da administração central dessa instituição são formados pelo Conselho Superior (Consup), pelo Colégio de Dirigentes (Codir) e Conselho de Ensino, Pesquisa e Extensão (Consepe). O Consup é um órgão colegiado, de caráter consultivo e deliberativo, cuja finalidade consiste em analisar e regular as diretrizes de atuação de cada instituto federal no âmbito acadêmico e administrativo, sendo composto por "representantes dos docentes, dos estudantes, dos servidores técnico-administrativos, dos egressos da instituição, da sociedade civil, do Ministério da Educação e do Colégio de Dirigentes do Instituto Federal”. O Codir por sua vez consiste em um órgão de apoio ao processo decisório da Reitoria “composto pelo Reitor, pelos Pró-Reitores e pelo Diretor-Geral de cada um dos campi que integram o Instituto Federal" e tem somente caráter consultivo. Subordinada ao Consup, a Reitoria, órgão executivo máximo da instituição, é composta pelo reitor e cinco próreitores, que realizam a administração, a coordenação e a supervisão de todas as atividades desenvolvidas pela autarquia. (HEEREN, 2019).

A partir do entendimento sobre a natureza jurídica dos Institutos Federais, se faz importante refletirmos sobre o conceito de autonomia presente no texto da Lei 11.892/08. O conceito de autonomia "pressupõe a liberdade de agir ou, em outras palavras, a possibilidade de autogestão, autogoverno, autonormação, ocorrendo em sistemas relacionais, em contextos de interdependência" (SILVA, 2009). Assim posto, em um contexto relacional, a autonomia se revela relativa.

Fica evidente, portanto, que existem indicações jurídico-normativas que permitem aos Institutos Federais a manutenção da sua política curricular em detrimento à aceitação das imposições induzidas pela Reforma do Ensino Médio, convalidando assim o relativo grau de autonomia e as prerrogativas dos Institutos Federais diante da sua atuação político-pedagógica necessária para a consolidação das suas finalidades institucionais.

A Reforma do Ensino Médio não se configura como uma realidade genuinamente brasileira. Em se tratando da América Latina, o Chile foi o pioneiro no que se refere a promoção de mudanças no cenário educacional.

No Chile, inicialmente, mesmo sob o regime ditatorial de Pinochet, a reforma se deu via processo de descentralização e privatização. A municipalização do sistema educativo fundamental e médio na década de 80 que até então era ligado ao governo federal - configurou, não só para o magistério, como para significativa parte da sociedade civil chilena, uma tática 
para livrar o governo de sua responsabilidade em relação ao financiamento educacional, provocando a deterioração da qualidade do trabalho docente e, por consequência, um atraso na qualidade da educação. (ZIBAS, 2002). ${ }^{1}$

Segundo Rojas Figueroa (1997), o processo de privatização se instalou mediante considerável transferência de fundos públicos para o sistema privado, como ocorre hoje no Brasil via Parceria Público Privada, de tal modo que, a partir de 1981, o velho e restrito sistema de subsídios públicos a algumas escolas particulares espalhou-se a toda uma nova rede privada de ensino. Diante desta constatação, o primeiro governo eleito, pós-Pinochet, impedido politicamente para alterar a Constituição, escolheu acolher a nova estruturação do sistema educacional, focando esforços num acordo salarial e trabalhista considerado mais justo para os professores.

Tal fase é considerada por Rojas Figueroa (1997) de fase de "resignação", uma vez que inexistia forma de fazer alterações na privatização da educação estabelecida pela ditadura, de forma a atenuar os efeitos negativos. Contudo, no fim do primeiro governo democrático, acontece o que o autor denomina de "consentimento" ou adesão às novas forças governistas no começo da privatização, mediante votação de lei que permitia as instituições particulares subvencionados a cobrar mensalidades, sem que o acréscimo de renda proveniente dessa cobrança se exprimisse em redução da subvenção. Fica evidente que o governo resguardou mais o sistema particular do que a ditadura, já que esta, ao decidir por cortes significativos da subvenção em casos de cobrança de taxas às famílias, buscava enfraquecer tal procedimento. (ZIBAS, 2002).

No Brasil, o exemplo chileno passou a ser explorado no início da década de 90, por autores que visualizavam na privatização a saída para a má qualidade do ensino público. Tedesco (1991) sustenta a tese segundo a qual “... as escolas privadas... [subvencionadas/chilenas] logram compensar as diferenças melhor do que as públicas” (p. 38). Da mesma forma Mello (1990) defende a fórmula chilena de transferência de fundos públicos para o sistema privado de ensino, enfatizando que o ensino médio poderia ser beneficiado por políticas privatizantes. Como consequência, os empresários da educação insistem na

\footnotetext{
${ }^{1}$ As parcerias público-privadas, amplamente utilizadas no contexto educativo em todo Brasil, consistem em um dos principais instrumentos utilizados pelo Estado brasileiro para realizar investimentos públicos junto à iniciativa privada. Por intermédio de uma PPP, a União, os Estados ou os Municípios podem selecionar e contratar empresas privadas que ficarão responsáveis pela prestação de serviços de interesse público por prazo determinado. As principais leis que regem as PPPs são as Leis Federais nº 8.987/1995 e n ${ }^{\circ}$ 11.079/2004.
} 
legitimidade da tese do financiamento público das escolas particulares, alegando sempre a reforma do Chile como modelo a ser seguido.

Contudo, os organismos internacionais, em especial o Banco Mundial, consistem nos principais mobilizadores de argumentos favoráveis à privatização, conforme exemplo chileno, e à introdução da estrutura de mercado nos sistemas educacionais públicos, persistindo na cobrança de taxas dos alunos do ensino médio. Diante do exposto, a reiteração de referências ao Chile, como exemplo de sucesso a ser adotado pela América Latina- incluindo aqui o Brasil, abona as iniciativas de se focalizar a reforma implementada naquele país.

\section{CONSIDERAÇões FinAIS}

Tendo em vista que esta investigação teve por objetivo evidenciar os impactos da Reforma do Ensino Médio - REM no Ensino Médio Integrado - EMI nos Institutos Federais IF`s, após a análise, na perspectiva de verificar se a mesma se refere a uma possibilidade de ressignificação da oferta, ou se trata-se do fim do Ensino Médio Integrado nos Institutos Federias, foi possível constatar que a Lei 13.415/17 alterou alguns artigos da LDB em especial no que se refere ao capítulo II, que orienta a educação básica, e, também, a seção IV, que trata especificamente do ensino médio propedêutico sem alterar os artigos relativos à seção IV-A que trata da educação profissional técnica de nível médio.

O artigo 36-B da seção IV menciona que a educação profissional técnica de nível médio deverá observar os objetivos e definições contidos nas diretrizes curriculares nacionais estabelecidas pelo Conselho Nacional de Educação; as normas complementares dos respectivos sistemas de ensino e as exigências de cada instituição de ensino, nos termos do seu projeto pedagógico. Assim, a Resolução CNE/CEB n. ${ }^{\circ}$ 06/2012, define as Diretrizes Curriculares Nacionais para a educação profissional técnica de nível médio, na mesma perspectiva, irá nortear as normas complementares de cada instituto federal, assim como dos projetos pedagógicos de cada campus.

Nessa direção, a lei relativa à Reforma do Ensino Médio não evidencia as conexões entre as diferentes modalidades e formas de organização curricular em se tratando do ensino médio integrado, concomitante e subsequente, já definidas na educação profissional e os eixos de formação criados para "o novo ensino médio".

Tal diferença não prevista pela reforma do ensino médio na organização curricular evidencia certa contradição no que tange à perspectiva de formação integral do estudante, já mencionada anteriormente neste texto, indicada no $§ 7$ do artigo 35-A da LDB. 
Diante do exposto, antagonicamente, a reforma, da forma como se apresenta, não leva em consideração as bases da formação integral, acentuando a dualidade da educação e a exclusão social de estudantes que historicamente sofrem em função da falta da educação de qualidade em uma perspectiva emancipadora, na perspectiva de um direito social determinado por lei.

\section{REFERÊNCIAS}

CUNHA, Luiz Antônio. O ensino de ofícios nos primórdios da industrialização. São Paulo: Editora UNESP, Brasília, DF: Flocos, 2000.

FERREIRA, Nilce Vieira Campos. Economia Doméstica: ensino profissionalizante feminino no triângulo mineiro (Uberaba/MG - 1953-1997). Jundiaí: Pacto Editorial, 2014.

GENNEP, Van Arnold. Os Ritos de Passagem. Coleção Antropologia, Petrópolis: Vozes, 1978.

HEEREN, Marcelo Velloso; SILVA, Marta Leandro da. O princípio de autonomia dos institutos federais e sua política educacional em oposição à reforma do ensino médio. Jornal de Políticas Educacionais. V. 13, n. 10. Março de 2019.

LIMA FILHO, Domingos Leite. É necessário resistir ao empobrecimento do currículo. GUIMARÃES, Cátia. EPSJV/Fiocruz. 06/ mar. 2017. Disponível em:

LIMA, Licínio Carlos; AFONSO, Almerindo Janela. Políticas públicas, novos contextos e actores em educação de adultos, In: LIMA, Licínio C. (Org.). Educação não-escolar de adultos. Iniciativas de educação e formação em contexto associativo. Braga: Universidade do Minho/Unidade de Educação de Adultos, 2006.

MELLO, Guiomar Namo de. Social democracia e educação. São Paulo: Cortez, 1990.

MOURA, Dante Henrique. Educação básica e educação profissional e tecnológica: dualidade histórica e perspectiva de integração. Holos, Natal, v. 2, p. 1-27, 2007. Disponível em: <http://www2.ifrn.edu.br/ojs/index.php/HOLOS/article/viewFile/11/110>. Acesso em 22 jun. 2017.

OJ - OBSERVATÓRIO DA JUVENTUDE. Reforma do Ensino Médio - MP 746/2016. Texto elaborado por professores da Faculdade de Educação da UFMG. Belo Horizonte, dezembro de 2016. Disponível em: <http://observatoriodajuventude.ufmg.br/texto-paradiscussao-reforma-do-ensino-medio-mp-7462016/>. Acesso em: 12 out. 2019.

RAMOS, Marise Nogueira. Ensino Médio Integrado: lutas históricas e resistências em tempos de regressão. In: ARAÚJO, A.C.; SILVA, C.N. (Orgs.). Ensino Médio Integrado no Brasil: fundamentos, práticas e desafios. Brasília: Ed. IFB, 2017. p. 20-43.

SILVA, Caetana Juracy Rezende: Institutos Federais: lei 11.892, de 29/12/2018, comentários e reflexões. Natal: IFRN, 2009. 
TEDESCO, Juan Carlos. Educación y sociedad del conocimiento y de la información. Trabalho apresentado no Encontro Internacional de Educación Media. Bogotá: Secretaria de Educación, 1999.

ZIBAS, Dagmar. A Reforma do Ensino Médio no Chile: Vitrina Para a América Latina? Cadernos de Pesquisa, n. 115, março/ 2002 Cadernos de Pesquisa, n. 115, p. 233-262, março/ 2002.

\section{DOCUMENTOS E LEIS}

BRASIL. Portaria $\mathbf{N}^{\circ} \mathbf{1 . 4 3 2}$ de 28 de dezembro de 2018. Estabelece os referenciais para elaboração dos itinerários formativos conforme preveem as Diretrizes Nacionais do Ensino Médio. Brasília, 2018.

BRASIL. Lei $\mathbf{n}^{\mathbf{0}}$ 13.415, de 16 de fevereiro de 2017. Altera a Lei $\mathrm{n}^{\circ}$ 9.394, de 20 de dezembro de 1996, que estabelece as diretrizes e bases da educação nacional. Brasília, 2017.

BRASIL. Base Nacional Comum Curricular (BNCC). Ministério da Educação (MEC). Brasília, DF, 2017.

BRASIL. Medida Provisória no 746, de 22 de setembro de 2016. Diário Oficial da União, Brasília: 23 de setembro de 2016.

BRASIL. Plano Nacional de Educação. Aprovado pela Lei no 13.005 , de 25 de junho de 2014. Brasília, 2014.

BRASIL. Resolução CNE/CEB n⿳0 6, de 20 de setembro de 2012. Define Diretrizes Curriculares Nacionais para a Educação Profissional Técnica de Nível Médio. Brasília, 2012.

BRASIL. Projeto Lei No 6840 de 2013. Altera a Lei no 9.394, de 20 de dezembro de 1996, que estabelece as diretrizes e bases da educação nacional, para instituir a jornada em tempo integral no ensino médio, dispor sobre a organização dos currículos do ensino médio em áreas do conhecimento e dá outras providências. Brasília 2013.

BRASIL. Lei no 11.892, de 29 de dezembro de 2008. Institui a Rede Federal de Educação Profissional, Científica e Tecnológica, cria os Institutos Federais de Educação, Ciência e Tecnologia, e dá outras providências. Brasília, 2008.

BRASIL. Lei $\mathrm{N}^{\mathrm{o}} 11.741$ de 16 de julho de 2008. Altera dispositivos da Lei n⿳0 9.394, de 20 de dezembro de 1996, que estabelece as diretrizes e bases da educação nacional, para redimensionar, institucionalizar e integrar as ações da educação profissional técnica de nível médio, da educação de jovens e adultos e da educação profissional e tecnológica. Brasília, 2008.

BRASIL. Lei no 11.494, de 20 de junho 2007. Regulamenta o Fundo de Manutenção e Desenvolvimento da Educação Básica e de Valorização dos Profissionais da Educação FUNDEB. Brasília, 2007.

BRASIL. Decreto $\mathbf{n}^{\circ} \mathbf{6 . 0 9 5}$ de 24 de abril de 2007. Estabelece diretrizes para o processo de integração de instituições federais de educação tecnológica, para fins de constituição dos 
Institutos Federais de Educação, Ciência e Tecnologia - IFET, no âmbito da Rede Federal de Educação Tecnológica. Brasília, 2007.

BRASIL. Decreto $\mathbf{N}^{0} 5.154$ de 13 de julho de 2004. Regulamenta o $\S 2$ o do art. 36 e os arts. 39 a 41 da Lei no 9.394, de 20 de dezembro de 1996, que estabelece as diretrizes e bases da educação nacional, e dá outras providências. Brasília, 2004.

BRASIL. Constituição Federal de 1988. Brasília, DF, 1988.

BRASIL. Decreto $\mathbf{n}^{\mathbf{0}} \mathbf{2 . 2 0 8}$, de 17 de abril de 1997. Regulamenta o $\S 2^{\circ}$ do artigo 36 e os artigos 39 a 42 da Lei ${ }^{\circ}$ 9.394, de 20 de dezembro de 1996, que estabelece as diretrizes e bases da educação nacional. Diário Oficial [da] República Federativa do Brasil, 18 abr. 1997.

BRASIL. Lei $\mathbf{n}^{\circ}$ 9.394, de 20 de dezembro de 1996. Estabelece as diretrizes e bases da educação nacional. Brasília, 1996

BRASIL. Lei no 8.948 de 08 de dezembro de 1994. Dispõe sobre a instituição do Sistema Nacional de Educação Tecnológica e dá outras providências. Brasília, 1994.

BRASIL. Decreto N $^{\circ} 200$ de 16 de fevereiro de 1967. Dispõe sobre a organização da Administração Federal, estabelece diretrizes para a Reforma Administrativa e dá outras providências. Brasília, 1967.

BRASIL. Decreto no 7.566, de 23 de setembro de 1909. Cria nas capitais dos Estados as Escolas de Aprendizes Artífices, para o ensino profissional primário e gratuito. De 23 de Setembro de 1909.

Recebido em: 15 de outubro de 2019.

Aprovado em: 16 de dezembro de 2019. 